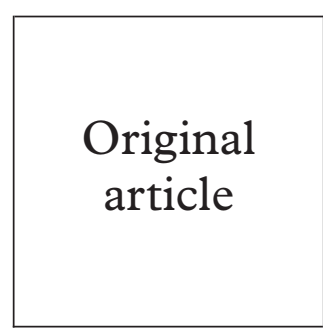

\title{
Risky business: health and safety in the sex industry over a 9 year period
}

\author{
Helen Ward, Sophie Day, Jonathan Weber
}

Objectives: To assess whether a previously established low sexually transmitted infection/HIV risk in prostitutes in London has been sustained, and to measure other occupational risks, including mortality.

Design: 9 year prospective study in west London.

Subjects: 402 prostitutes recruited from 1985 to 1991, 320 were followed up for 675 person years to 1994 .

Main outcome measures: Condom use in commercial and non-commercial sex; viral and bacterial sexually transmitted infection at initial and follow up visits; death.

Results: Condom use increased significantly from 1986 to 1993 and protected the majority of commercial sexual contacts. Baseline prevalence: HIV 1.3\%, hepatitis C $6.7 \%$, hepatitis B $6.6 \%$, syphilis $2.3 \%$, HTLV-I/II $0.4 \%$, gonorrhoea $3.0 \%$, chlamydia $8.2 \%$, genital herpes $16.8 \%$. Incidence (per 100 person years): HIV 0.2, hepatitis C 0.3, gonorrhoea 5.6, chlamydia 12.6, genital herpes 6.5. Viral infections were associated with injecting drug use and non-British nationality; bacterial infections were associated with numbers of non-commercial partners but not with sexual contacts at work. Four women died during the course of the study; two had AIDS, two were murdered. This mortality of 5.93 per 1000 person years was 12 times the expected rate for women of a similar age.

Conclusions: This study shows that it is possible to have a large number of sexual partners and remain free from sexually transmitted infections provided that condoms are used consistently: there has been a sustained increase in condom use in the sex industry. None the less, prostitutes are at increased risk of sexually transmitted infections, primarily through non-commercial sexual partnerships. Infectious diseases are only one of the risks facing prostitutes, as illustrated by the mortality from violence as well as from HIV infection.

(Sex Transm Inf 1999;75:340-343)

Keywords: health and safety; sex industry; prostitution; condoms

\section{Introduction}

It is generally accepted that people with a higher number of sexual partners are at increased risk of sexually transmitted infections, including HIV. Epidemiological models have explained the persistence of some bacterial infections, such as gonorrhoea, by the activity of core groups who contribute disproportionately to the transmission of infection. ${ }^{1-6}$ Prostitutes are generally assumed to be part of this core group. ${ }^{78}$ However, reported rates of infection in prostitute populations vary, ${ }^{9}$ and prostitutes are most at risk of HIV in situations of widespread heterosexual transmission, where control of other sexually transmitted infection is poor. ${ }^{10-12}$ In the United Kingdom, Western Europe, North America, and Australasia the prevalence of HIV has been lower in heterosexual men and women than in many developing countries, ${ }^{13}{ }^{14}$ although the pattern may be changing in some countries. ${ }^{15} 16 \mathrm{We}$ have previously reported a relatively low prevalence of HIV in female prostitutes in London. ${ }^{17}{ }^{18}$ In this article, we analyse data from a cohort study to assess whether the low sexually transmitted infection/HIV risk is sustained over time.

\section{Subjects and methods}

From 1985 to the end of 1991, women working as prostitutes were enrolled in a cohort study based in an inner London genitourinary medicine department, where a special clinical and outreach service, the Praed Street Project, was developed for prostitutes. ${ }^{19}$ Women were eligible for the study if they defined themselves as prostitutes and had worked within the past 3 months. Duration of follow up was calculated from the date of first visit to the most recent visit until the beginning of 1994, or date of death. While it was not possible to establish whether the study was strictly representative of the local sex industry, methods of recruitment were as inclusive as possible so that participants were drawn from all types of workplace in the area.

After consenting to the research, women were interviewed using a semistructured schedule covering social and demographic background, prostitution, sexual and medical histories. Participants were offered screening for sexually transmitted infection with informed consent, and a proportion consented to the storage of serum for future testing. Participants were asked to attend every 3 months for repeat interview and examination but, in reality, most women attended when they wanted a check up.

Screening was based on routine diagnostic methods for most infections. Gonorrhoea was detected using Gram stain with culture confirmation. Direct immunofluorescence was used to detect chlamydia from cervical specimens, 
Table 1 Description of prostitutes in the cohort $(n=320)$ and those who made one visit only $(n=82)$, (based on information from first visit)

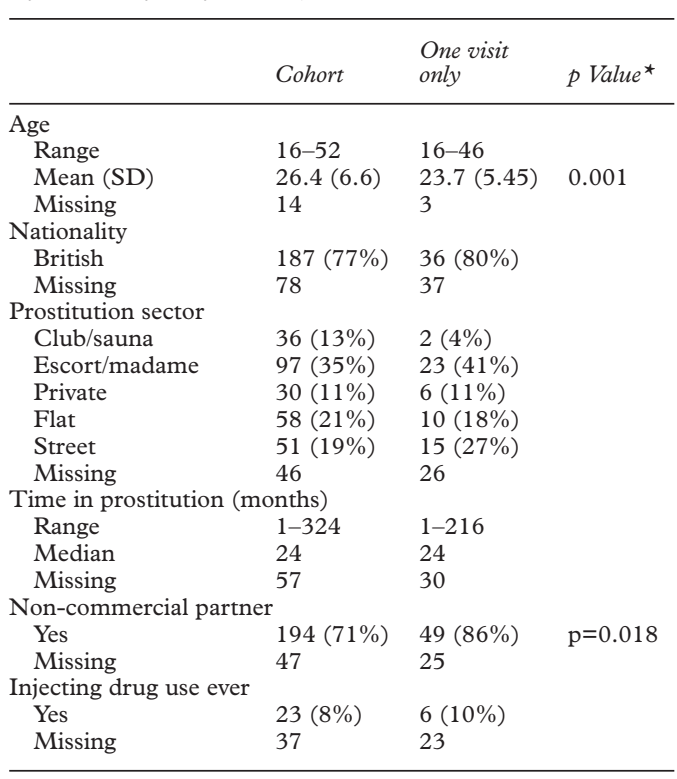

and trichomoniasis was diagnosed through direct microscopy of a wet mount from vaginal secretions. A diagnosis of new genital herpes was based on positive culture from a clinical lesion in someone with no previous history. Serum samples were tested for antibodies to HIV-1 and 2 using routine ELISA screening tests with confirmation; hepatitis B core antibody was used as evidence of past infection; syphilis was diagnosed using TPHA, VDRL, and FTA. The most recent stored serum sample from each individual was tested for HTLV-I and HTLV-II infection, first with a particle agglutination assay, and reactive sera were further investigated with an HTLV-I/II EIA. ${ }^{20}$ Stored sera were also screened for hepatitis $\mathrm{C}$ infection, using second or third generation ELISA confirmed using a third generation RIBA.

Information on mortality was based on incidental reports from other prostitutes; routine mortality records could not be used for reasons of confidentiality. The estimated mortality was compared with routine statistics for women aged $15-44$ in Greater London. ${ }^{21}$

Data were stored in a database and analysed using sPss. Simple univariate analysis was carried out for most comparisons. Continuous variables were compared using $t$ tests, or non-parametric tests (Mann-Whitney U test), variables were included in logistic regression models if they were associated in univariate analysis and retained if they were significant or had a major effect on the log likelihood ratio.

\section{Results}

From 1985 to 1991,402 women were recruited, 320 of whom completed 2921 visits (range 2-129) and are considered part of the cohort. By 1994, we had observed these 320 women for 675 years of follow up (median 18 months, range 1-100 months).

Table 1 compares women who became part of the cohort with those seen once. Women who remained in the cohort were older (mean
Table 2 Condom use for vaginal intercourse with clients and non-commercial partners

\begin{tabular}{lllll}
\hline & \multicolumn{2}{l}{ Number of visits where } & 100\% condom use reported \\
\cline { 2 - 5 } Year & Clients* & \multicolumn{3}{c}{ Non-commercial partnerst } \\
\hline 1986 & $72 / 107$ & $67 \%$ & $7 / 81$ & $9 \%$ \\
1987 & $125 / 164$ & $76 \%$ & $12 / 149$ & $8 \%$ \\
1988 & $100 / 116$ & $86 \%$ & $5 / 107$ & $5 \%$ \\
1989 & $229 / 249$ & $92 \%$ & $22 / 200$ & $11 \%$ \\
1990 & $322 / 343$ & $94 \%$ & $37 / 314$ & $12 \%$ \\
1991 & $327 / 345$ & $95 \%$ & $36 / 341$ & $11 \%$ \\
1992 & $243 / 265$ & $92 \%$ & $47 / 293$ & $16 \%$ \\
1993 & $94 / 104$ & $90 \%$ & $16 / 99$ & $16 \%$ \\
\hline
\end{tabular}

$\star \chi^{2}$ for linear trend $=63.5, \mathrm{p}<0.0001$

$+\chi^{2}$ for linear trend $=10.4, \mathrm{p}<0.001$

difference 2.6 years, 95\% confidence interval (CI) for the difference 1.1, 4.2, $t=3.28$ ) and less likely to have a non-commercial partner (odds ratio $(\mathrm{OR})=0.88,95 \%$ CI $0.80,0.97$, likelihood ratio 5.63), but there were no other significant differences.

The total numbers of clients seen for all types of sex reported by participants in the week before 2311 visits (data were missing for 610 visits) was 23621 , mean 10.2, median 5 . Most of these contacts were protected through the use of condoms, which increased significantly over time as shown in table 2 . Condom breakages in the past month were reported at $492(29 \%)$ of 1687 visits. This information was systematically collected from 1988 onwards, and there was no change in the proportion of visits where condom failures were reported over subsequent years. Women reporting condom failures had significantly more vaginal sex with clients (mean 9.5 per week compared with 6.8 , mean difference $2.7,95 \%$ CI for the difference $1.6,3.9, t=4.53, \mathrm{p}<0.001)$.

Women reported sexual contact with one or more non-commercial male partners (boyfriends, husbands, or casual partners) in the previous month at $68 \%$ of visits $(1640 / 2398)$. Table 2 shows that condom use with these partners doubled from $8 \%$ in 1986 to $16 \%$ in 1992.

Table 3 shows baseline prevalence and incidence rates for HIV, hepatitis B and C, HTLV-I/II, syphilis, and other sexually transmitted infections. Of the four women initially infected with HIV, three were probably infected through injecting drug use, and one from a non-commercial partner. There were no significant differences in the likelihood of having a test by history of injecting drug use, noncommercial partners, age, nationality, or prostitution sector. Repeat HIV tests were carried out for 162 women (range 2-13 tests) over a combined follow up period of 432 person years. One woman acquired HIV during the study; she reported one broken condom with a client 3 months before her first positive test, and unprotected sex with three noncommercial partners, including one from a country with a high prevalence of HIV.

Hepatitis C infection was associated with injecting drug use, which was reported by 12 of the 15 initially positive, and by the one woman who acquired the infection (OR for the association $134,95 \%$ CI 25,845$)$. Two other women with hepatitis $\mathrm{C}$ had a history of blood transfu- 
Table 3 Baseline prevalence and incidence of infections

\begin{tabular}{llllllll}
\hline & \multicolumn{3}{l}{ Baseline prevalence } & & & Incidence \\
\cline { 2 - 3 } & $\begin{array}{l}\text { Number } \\
\text { tested }\end{array}$ & $\begin{array}{l}\text { Number } \\
\text { positive }\end{array}$ & Prevalence & $\begin{array}{l}\text { Person years } \\
\text { follow up }\end{array}$ & $\begin{array}{l}\text { Incident } \\
\text { cases }\end{array}$ & $\begin{array}{l}\text { Incidence (per 100 } \\
\text { person years) }\end{array}$ \\
\hline HIV & 312 & 4 & $1.3 \%$ & & 432 & 1 & 0.23 \\
Hepatitis C & 225 & 15 & $6.7 \%$ & & 320 & 1 & 0.31 \\
Hepatitis B & 320 & 21 & $6.6 \%$ & & NA* & & \\
Syphilis & 390 & 9 & $2.3 \%$ & & 530 & 0 & 0 \\
HTLV-I/II & 256 & 1 & $0.4 \%$ & & 274 & 0 & 0 \\
Gonorrhoea & 402 & 12 & $3.0 \%$ & & 675 & 38 & 5.6 \\
Chlamydia & 402 & 33 & $8.2 \%$ & 675 & 85 & 12.6 \\
Genital herpes & 298 & $50 \dagger$ & $16.8 \%$ & $460 \ddagger$ & 30 & 6.5 \\
\hline
\end{tabular}

*Women were offered vaccination for hepatitis B.

†Number reporting a past history of genital herpes.

$\ddagger$ Excludes those with past history of genital herpes.

sion; the third was from South America and had no specific risk factors. Hepatitis B infection was associated with a history of injecting drug use (OR 7.7, 95\% CI 3.0, 21.2), and non-UK nationality (OR 3.57, 95\% CI $1.4,9.1)$.

There were 50 cases of gonorrhoea in 39 women, 118 cases of chlamydia in 86 women, and 31 cases of primary genital herpes. In a multivariate analysis gonorrhoea infection was associated with increasing numbers of noncommercial partners (RR 2.30, 95\% CI 1.41, 3.76. $\mathrm{p}<0.001)$, and earlier years of the study. There was no association with condom use (with clients or non-commercial partners). Chlamydial infection was significantly associated with having a non-commercial partner.

Four women are known to have died during the course of the study, a mortality of 5.93 per 1000 person years. Compared with estimated mortality for women aged 15 to 44 in Greater London in 1992, this is a relative risk of 12.15 (95\% CI 4.6, 32.4). Two were women with HIV infection who developed AIDS. The other two were murdered; one was killed by her boyfriend, no one has been convicted of the other murder. These women were at no obvious risk of violent death; both worked through referral and avoided public soliciting; neither injected drugs.

\section{Discussion}

A relatively low prevalence of HIV infection has been established previously among female prostitutes working in the United Kingdom. ${ }^{14}{ }^{18}$ This study provides additional evidence that it is possible to work in the sex industry, and to have a high rate of partner change (over 250 clients per year), and remain uninfected with HIV. This study shows that high levels of condom use can be achieved in commercial sex and sustained over time. Condom use with non-commercial partners also increased, although to a much lower level. Condom failures were reported by women at almost $30 \%$ of visits. This may be an overestimate of failure rates, as the breakage may have prompted attendance at the clinic for a check up, and reported failure may also reflect difficulties in disclosing unprotected sex with clients.

Even though the risk of sexually transmitted infection in this group is relatively low compared with many groups of prostitutes, it is higher than the general population risks in the
United Kingdom, and represents a degree of avoidable morbidity and mortality. The rate of HIV, for example, is eight times higher than for women having babies in inner London from 1988 to 1993 , and twice the rate in women attending genitourinary medicine clinics from 1990 to $1993 .^{22}$

The increased infection risks that we have reported are associated only indirectly with sex work. For example, prostitutes are at risk of HIV, hepatitis B and C infection primarily from injecting drug use, not sex with clients. The criminal status of the sex industry strengthens links between prostitution and other criminal activities, such as the distribution and use of illicit drugs. ${ }^{23}{ }^{24}$ Similarly, prostitutes are at risk of HIV and other sexually transmitted infections through sex with their non-commercial partners. ${ }^{18}$

The high mortality observed in this study is striking; the four deaths illustrate that infectious diseases are only one of the occupational risks facing prostitutes. The two murders provide extreme examples of common experiences among prostitutes, who face high rates of violent assault in their personal and their professional lives not just because they are prostitutes, but also because they are women, and may be drug users, homeless, young, and poor. ${ }^{25}$ The health risks of this occupation are both direct and indirect; occupational studies of, and services for, prostitutes cannot be confined to the risks posed directly by exchanges with customers.

This study was supported by the Medical Research Council, AVERT, North West Thames Regional Health Authority, Jefferiss Research Trust. Sophie Day is supported by the Jefferiss Research

Thanks to all participants, and to the many collaborators who have contributed to this work over the years: S Adam, P Aylin, have contributed to this work over the years: S Adam, P Aylin, S Barton, E Claydon, A de la Court, C Donegan, L Dunlop,
S Farrar, D Goldmeier, J R W Harris, M Hickey, C Ison, D Jeffries, C Kenny, J Mezzone, D Miller, A Pallecaros, G Taylor, D Taylor-Robinson, B Thomas, J Wadsworth, P Watkins, L Whitaker.

1 Garnett GP, Anderson RM. Sexually transmitted diseases and sexual behaviour: insights from mathematical models. $\mathcal{F}$ Infect Dis 1996;174:S150-61.

2 Yorke JA, Hethcote HW, Nold A. Dynamics and control of the transmission of gonorrhoea. Sex Transm Dis 1978;5:518 .

3 Brunham RC. The concept of core and its relevance to the epidemiology and control of sexually transmitted diseases. Sex Transm Dis 1991;18:67-8.

4 Thomas JC, Tucker MJ. The development and use of the concept of a sexually transmitted disease core. F Infect Dis 1996;174 (Suppl 2):S134-43.

5 Zenilman JM, Bonner M, Sharp KL, et al. Penicillinaseproducing Neisseria gonorrhoeae in Dade County, Florida: evidence of core group transmitters and the impact of illicit antibiotics. Sex Transm Dis 1988;15:45-50.

6 Rothenberg RB. The geography of gonorrhoea. Am f Epidemiol 1983;117:688-94.

7 Moses S, Plummer FA, Ngugi EN, et al. Controlling HIV in Africa: effectiveness and cost of an intervention in a Africa: effectiveness and cost of an intervention in a high-frec

8 Aral SO and Holmes KK. Epidemiology of sexual behaviour and STD. In: KK Holmes et al, eds. Sexually transmitted diseases. 2nd ed. New York: McGraw Hill, 1990.

9 Day S, Ward H. STD control and commercial sex workers. Genitourin Med 1997;73:161-8.

10 Djomand G, Greenberg AE, Sassan-Morokro M, et al. The epidemic of HIV/AIDS in Abidjan, Cote d'Ivoire: a review of data collected by Projet RETRO-CI from 1987 to 1993 f Acquir Immune Defic Syndr Hum Retrovirol 1995;10:35865.

11 Rodrigues JJ, Mehendale SM, Shepherd ME, et al. Risk factors for HIV infection in people attending clinics for sexutors for HIV infection in people attending clinics for sexu-

12 Celantano DD, Akarasewi P, Sussman L, et al. HIV-1 infection among lower class commercial sex workers in Chiang Mai, Thailand. AIDS 1994; 8:533-7. 
13 Philpot CR, Harcourt CL, Edwards JM. A survey of female prostitutes at risk of HIV infection and other sexually transmissible diseases. Genitourin Med 1991;67:384-8.

14 European Working Group on HIV Infection in Female Prostitutes. HIV infection in European female sex workers: epidemiological link with the use of petroleum-based lubricants. AIDS 1992;7:401-8.

15 Spina M, Mancuso S, Sinicco A, et al. Human immunodeficiency virus seroprevalence and condom use among female sex workers in Italy. Sex Transm Dis 1998:25:451-4.

16 Fennema JSA, Van Ameijden EJC, Coutinho RA, et al. Clinical sexually transmitted diseases among human Clinical sexully transmitted diseases among human immunodefiency virus-infected and nom using prostitutes: associated factors and interpretation

17 Day S, Ward H, Harris JRW. Prostitute women and public Day S, Ward H, Harris JRW.
health. BMF 1988;297:1585.

18 Ward H, Day S, Mezzone J, et al. Prostitution and risk of HIV: female prostitutes in London. BMF 1993;307:356-8. 19 Ward H, Day S. Health care and regulation-new perspectives. In: G Scambler, A Scambler, eds. Rethinking prostitution. London: Routledge, 1997: 139-64.
20 Taylor GP. The epidemiology of HTLV-I in Europe. $\mathcal{f}$ AIDS HIV Retrovir 1996;13:S8-14.

21 OPCS. Mortality statistics 1992. London: HMSO Series DH5 no 19.

22 Department of Health. Prevalence of HIV in England and Wales in 1997. Annual Report of the Unlinked Anonymous Prevalence Monitoring Programme (chair, J Metters) Prevalence Mondon, 1998 .

23 European Network for HIV/STD Prevention in Prostitution. Hustling for health: developing services for sex workers in Europe. London: Imperial College School of Medicine, 1999. See http://www.med.ic.ac.uk/df/dfhm/europap/ index.htm

24 Allen J. The making of a prostitute proletariat in the early twentieth century New South Wales. In: Daniels IT, ed. So much hard work. Sydney: Fontana, Collins, 1984.

25 Day S. What counts as rape? Physical assault and broken contracts: contrasting views of rape among London sex workers. In: P Harvey, P Gow, eds. Sex and violence: issues in representation and experience. London: Routledge, 1994. 